\title{
Atmospheric Lateral Diffusion Estimates from Tetroons ${ }^{1}$
}

\author{
J. K. Angell and D. H. Pack \\ U. S. Weather Bureau, Washington, D. C.
}

(Manuscript received 28 February 1964, in revised form 15 January 1965)

\begin{abstract}
Successive tetroon releases are utilized to provide an estimate of the lateral diffusion from a continuous point source as a function of downwind distance. On the average the tetroons yield a lateral standard deviation proportional to the $\mathbf{0 . 8 5}$ power of the downwind distance. The mean ratio of lateral standard deviation to downwind distance varies from 0.40 (5 km downwind) to 0.31 (40 km downwind) for tetroon releases over time intervals of 3 hours and from 0.64 to 0.49 for tetroon releases over time intervals of 21 hours. These mean ratios are large because of the preponderance of tetroon flights within the Los Angeles Basin. The data also imply a lateral standard deviation proportional to about the 0.2 power of the time interval of tetroon release and hence, to a first approximation, to about the 0.2 power of the sampling time.

The lateral standard deviations obtained from successive tetroon releases are compared to estimates derived from individual tetroon flights through evaluation of running means of the lateral velocity. The agreement is good at a downwind distance of $5 \mathrm{~km}$ but becomes progressively worse with increase in downwind distance so that, at a downwind distance of $20 \mathrm{~km}$, the average lateral standard deviation derived from the individual trajectories is only 70 per cent of that derived from the series.
\end{abstract}

\section{Introduction}

The use of the radar-tetroon-transponder system for obtaining air trajectories and wind statistics over relatively long times and distances has been established as a reasonably simple operational technique by Pack (1962), and Pack and Angell (1963). Recent developments include an extensive tetroon program at the Nevada Test Site of the Atomic Energy Commission, during which more than 200 tetroon flights were made, as reported by $\mathrm{H}$. Booth (personal communication, 1963), and, at the National Reactor Testing Station, Idaho Falls, the automatic tracking of tetroon-transponder flights to distances exceeding 50 miles by an M-33 radar, as reported by C. R. Dickson (personal communication, 1963). Thus, there is every indication that data of this type will become more numerous and more readily acquired. Consequently, in addition to the invaluable trajectory data, it is desirable to examine in some detail how the tetroon position data may be used to estimate atmospheric diffusion. The use of single tetroon flights to estimate lateral (and vertical) diffusion has been discussed by Angell (1962). This analysis will compare lateral diffusion estimates from series of consecutive tetroon flights to similar estimates from individual flights and attempt to provide practical guides on the limits of these techniques.

\footnotetext{
${ }^{1}$ Research undertaken as portions of programs sponsored by Reactor Development Division, Atomic Energy Commission, and Air Pollution Division, Public Health Service.
}

\section{Estimation of lateral diffusion from successive tetroon flights}

Successive tetroon flights from a given site may be utilized to approximate the lateral diffusion to be expected from a continuous point source. This is most obviously done through determination of a mean trajectory direction and evaluation of the root mean square of the lateral distances between individual trajectories and mean trajectory at various distances downwind. If a tetroon flight program is set up solely to determine diffusion characteristics, there is no difficulty in the above procedure since the tetroons can be released at equal time intervals for a specified period of time, thus permitting the objective determination of a mean trajectory. However, the tetroon flights so far available to us have not been made primarily for the study of diffusion, and consequently the flights have been released at unequal time intervals and for unspecified periods of time. This has not only made it difficult to define a mean trajectory objectively but has invited the criticism that the series of trajectories we have chosen to estimate the lateral diffusion have not been truly representative of all possible series.

In accordance with these criticisms, we have attempted to make our study of the lateral diffusion at various tetroon launch sites completely objective through utilization of an equation presented by Brier (1950). This equation states that the variance of a distribution of points is proportional to the sum of the 
squares of the differences between all possible pairs of points, or, in the case of the lateral $(y)$ direction,

$$
\sigma_{y}^{2}=\frac{1}{2} N^{-1}(X-1)^{-1} \sum_{i=1}^{N} \sum_{j=1}^{N}\left(Y_{i}-Y_{j}\right)^{2},
$$

where $N$ is the number of points. Through the use of this equation the problem of determining a mean trajectory is avoided. This equation also facilitates the evaluation of variances for various series covering various time intervals. The chief disadvantage of this method is that it does not provide a mean wind direction or "centerline" information.

The procedure adopted was as follows: Circles of radius $5,10,15 \mathrm{~km}$, etc., were drawn around each tetroon launch site. [Tables listing launch sites, dates and times of tetroon release, and the tracking duration of the tetroon flights utilized herein are to be found in articles by Angell and Pack (1961, 1962), Pack and Angell (1963) and Angell (1964).] The straight-line distance between points of intersection of pairs of tetroons trajectories with each circle was then evaluated for all pairs whose difference in release time did not exceed 24 hours. The lateral standard deviation as a function of downwind distance was next evaluated for all possible trajectory series through use of $\mathrm{Eq}$. (1). Thus, if five flights were made within a certain time interval, a total of 26 different series would be obtained, made up of 10 series consisting of 2 flights, 10 series consisting of 3 flights, 5 series consisting of 4 flights, and 1 series consisting of 5 flights. Obviously, there is considerable redundancy here inasmuch as one series will differ from another series only through the addition and/or subtraction of a single trajectory. However, we are no longer susceptible to the criticism of nonrepresentativeness since we have taken into account all possible series. In the following, wherever possible, we divide the data according to whether the tetroons are released over time intervals of between 0 and $6 \mathrm{hr}$, between 6 and $12 \mathrm{hr}$, between 12 and $18 \mathrm{hr}$, or between 18 and $24 \mathrm{hr}$. To a first approximation, then, the data refer to time intervals of tetroon release of $3,9,15$ and $21 \mathrm{hr}$.

While Eq. (1) permits the estimation of a lateral standard deviation from only two trajectories, one might well question the representativeness of lateral standard deviations derived in this manner. Some idea of the representativeness can be obtained from the simultaneous release of tetroons from Marineland within the Los Angeles Basin. Lateral standard deviations were computed for pairs of trajectories using first the evennumbered and then the odd-numbered flight of the simultaneous pairs. As an example, in the case of simultaneously released flights 75 and 76 , we compare the lateral standard deviation derived from flights 74 and 75 with the lateral standard deviation derived from flights 74 and 76 . The comparison is shown in Fig. 1, and suggests that in most cases the lateral standard

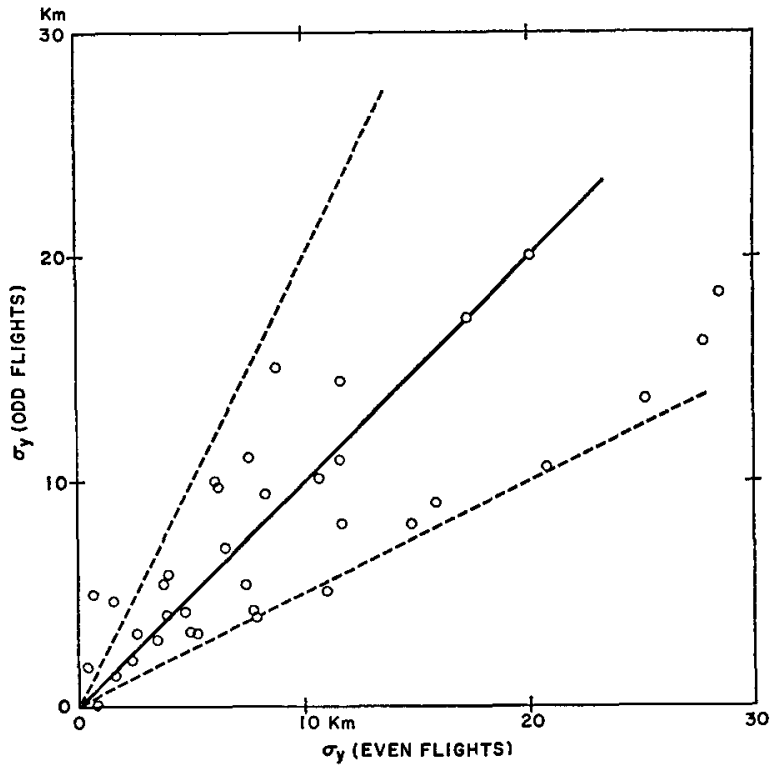

Fig. 1. Comparison of lateral standard deviations computed from trajectory pairs utilizing the even-numbered and oddnumbered flight of a simultaneously released tetroon pair. The dashed lines indicate a difference exceeding a factor of two.

deviation obtained from two trajectories will not be in error by more than a factor of two.

Fig. 2 shows, on a $\log$-log plot, the mean lateral standard deviation as a function of downwind distance for the various tetroon launch sites and for time intervals of tetroon release of 3 and $21 \mathrm{hr}$. In determining the mean lateral standard deviation at each downwind distance, the value obtained from each series was weighted according to the number of trajectories comprising that series. This appeared desirable since, the greater the number of trajectories in a series, the more reliable the lateral standard deviations derived therefrom. To avoid abrupt changes in lateral standard deviation values when series had to be eliminated due to the termination of individual trajectories within the series, we evaluated the average difference in lateral standard deviation with increase in downwind distance for the remaining series and applied this difference value to the terminated series. In Fig. 2 the vertical bars extend one standard deviation of the mean above and below the mean, thus giving some idea of the variability of the values obtained from individual series.

The tetroon trajectories from Long Beach, Marineland, and Venice (all within the Los Angeles Basin) indicate the large lateral standard deviations to be expected in a region with a pronounced diurnal wind regime. At Marineland and Venice the lateral standard deviation for the 21-hr series is much larger than for the 3-hr series. This is not true at Long Beach because many of the flights happened to be released within a 6-hr period of the land and sea breeze reversal. The numbers plotted within the boxes of Fig. 2 indicate the power describing the standard deviation versus the 


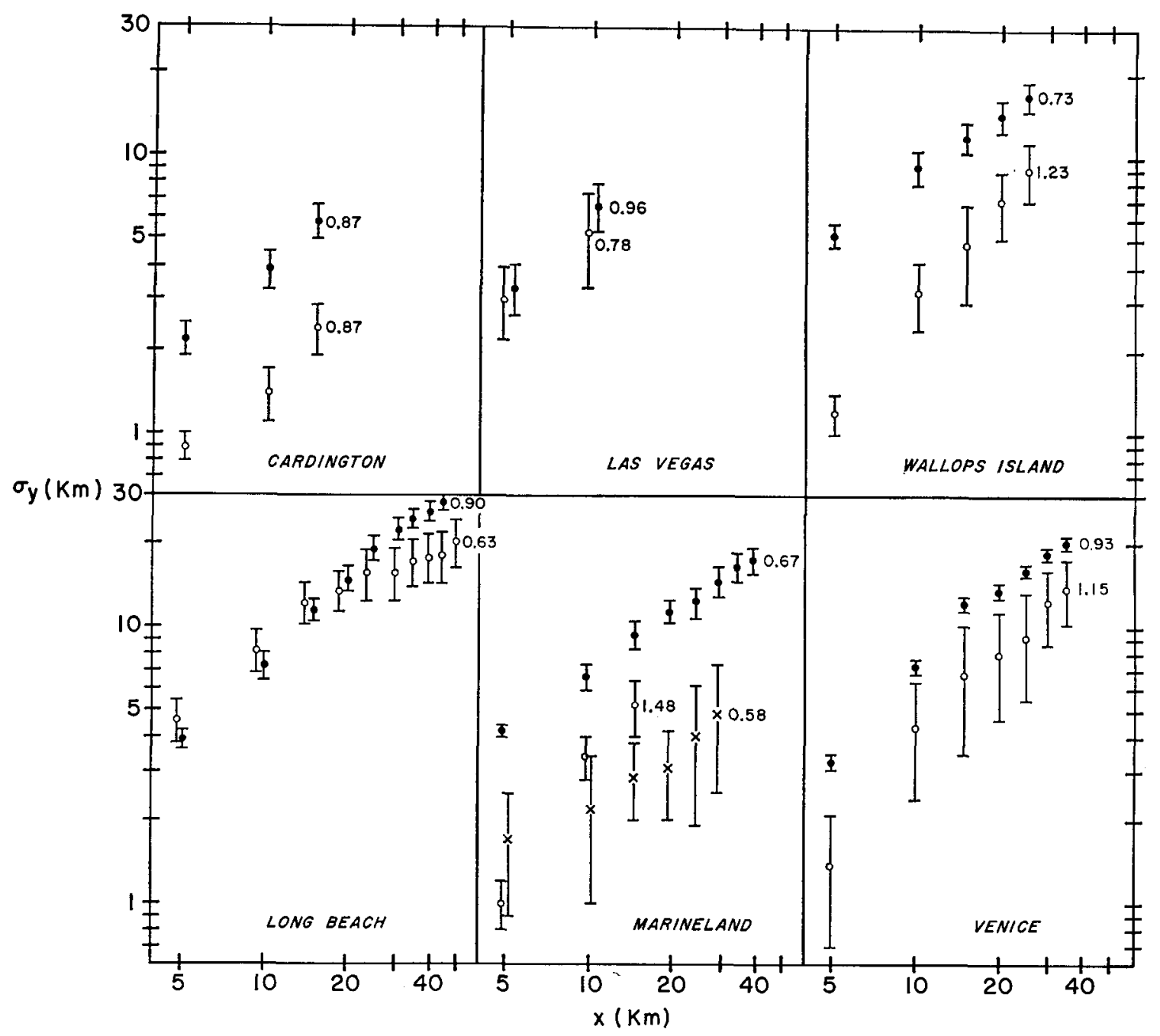

FIG. 2. Mean variation of lateral standard deviation with downwind distance for different tetroon launch sites and for time intervals of tetroon release averaging $3 \mathrm{hr}$ (circles), $21 \mathrm{hr}$ (dots) and for simultaneous releases (crosses). The vertical bar extends one standard deviation of the mean above and below the mean. The numbers indicate the power describing the standard deviation versus the downwind relationship.

downwind relationship, as derived from the difference in standard deviation at $5 \mathrm{~km}$ and at the maximum downwind distance plotted in Fig. 2. While there is considerable variability in this power, it has a median value of 0.88 , a value frequently quoted as applicable to a much smaller space and time scale. In the Marineland box we have also indicated the lateral standard deviation as a function of downwind distance for 4 pairs of simultaneously released tetroon flights. There is the peculiarity that at a downwind distance of $5 \mathrm{~km}$ the standard deviation for the simultaneous releases is greater than for the 3-hr series. This is surely not representative, as suggested by the magnitude of the standard deviation of the mean. In general, the increase of lateral standard deviation with downwind distance is considerably less for the simultaneous releases than for the successive releases, with the lateral standard deviation proportional to only the 0.58 power of the downwind distance in the former case.

In order to present the tetroon-derived lateral diffusion data in more accessible form, Table 1 was prepared, giving the mean ratio of lateral standard deviation to downwind distance, as a function of downwind distance, for various tetroon launch sites and time intervals of tetroon release. Worthy of attention is the tendency at Las Vegas and Venice for the lateral standard deviation to be greater for time intervals of tetroon release of 9 and 15 hours than for time intervals of 3 and 21 hours. This indicates the strength of the diurnal wind regime at these locations during the time of the tetroon flights. It is this combination of diurnal and synoptic changes in wind direction which, in general, yields such large values of the ratio in Table 1 . Only the flights from Cardington yield a ratio at all 
TABLE 1. Mean ratio of lateral standard deviation to downwind distance, as a function of downwind distance, for various tetroon launch sites and time intervals of tetroon release.

\begin{tabular}{|c|c|c|c|c|c|c|c|c|c|c|c|c|}
\hline \multirow{2}{*}{$\begin{array}{l}\text { Launch } \\
\text { site }\end{array}$} & \multirow{2}{*}{$\begin{array}{c}\text { Time } \\
\text { interval of } \\
\text { tetroon } \\
\text { release } \\
\text { (hours) }\end{array}$} & \multirow{2}{*}{$\begin{array}{l}\text { Number } \\
\text { of series }\end{array}$} & \multicolumn{10}{|c|}{ Downwind distance $(\mathrm{km})$} \\
\hline & & & 5 & 10 & 15 & 20 & 25 & 30 & 35 & 40 & 45 & 50 \\
\hline Cardington & $\begin{array}{r}3 \\
21\end{array}$ & $\begin{array}{l}16 \\
30\end{array}$ & $\begin{array}{l}0.18 \\
0.44\end{array}$ & $\begin{array}{l}0.14 \\
0.39\end{array}$ & $\begin{array}{l}0.24 \\
0.58\end{array}$ & & & & & & & \\
\hline Las Vegas & $\begin{array}{r}3 \\
9 \\
15 \\
21\end{array}$ & $\begin{array}{l}6 \\
4 \\
5 \\
6\end{array}$ & $\begin{array}{l}0.62 \\
0.78 \\
0.90 \\
0.68\end{array}$ & $\begin{array}{l}0.54 \\
0.78 \\
0.96 \\
0.67\end{array}$ & & & & & & & & \\
\hline Wallops Isl. & $\begin{array}{r}3 \\
21\end{array}$ & $\begin{array}{l}3 \\
3\end{array}$ & $\begin{array}{l}0.24 \\
1.06\end{array}$ & $\begin{array}{l}0.33 \\
0.93\end{array}$ & $\begin{array}{l}0.33 \\
0.80\end{array}$ & $\begin{array}{l}0.35 \\
0.72\end{array}$ & $\begin{array}{l}0.36 \\
0.68\end{array}$ & & & & & \\
\hline Long Beach & $\begin{array}{r}3 \\
9 \\
15 \\
21\end{array}$ & $\begin{array}{r}8 \\
9 \\
8 \\
14\end{array}$ & $\begin{array}{l}0.92 \\
0.80 \\
0.76 \\
0.78\end{array}$ & $\begin{array}{l}0.82 \\
0.66 \\
0.70 \\
0.72\end{array}$ & $\begin{array}{l}0.81 \\
0.69 \\
0.59 \\
0.76\end{array}$ & $\begin{array}{l}0.68 \\
0.69 \\
0.49 \\
0.74\end{array}$ & $\begin{array}{l}0.62 \\
0.69 \\
0.50 \\
0.76\end{array}$ & $\begin{array}{l}0.52 \\
0.67 \\
0.45 \\
0.74\end{array}$ & $\begin{array}{l}0.49 \\
0.62 \\
0.40 \\
0.69\end{array}$ & $\begin{array}{l}0.44 \\
0.60\end{array}$ & $\begin{array}{l}0.40 \\
0.58 \\
0.62\end{array}$ & $\begin{array}{l}0.40 \\
0.58\end{array}$ \\
\hline Marineland & $\begin{array}{r}0 \\
3 \\
21\end{array}$ & $\begin{array}{r}4 \\
7 \\
13\end{array}$ & $\begin{array}{l}0.34 \\
0.20 \\
0.84\end{array}$ & $\begin{array}{l}0.22 \\
0.34 \\
0.66\end{array}$ & $\begin{array}{l}0.19 \\
0.35 \\
0.62\end{array}$ & 0.16 & 0.16 & 0.16 & 0.47 & 0.43 & & \\
\hline Venice & $\begin{array}{r}3 \\
9 \\
15 \\
21\end{array}$ & $\begin{array}{l}4 \\
5 \\
4 \\
4\end{array}$ & $\begin{array}{l}0.28 \\
0.92 \\
0.88 \\
0.66\end{array}$ & $\begin{array}{l}0.44 \\
0.85 \\
0.84 \\
0.73\end{array}$ & $\begin{array}{l}0.43 \\
0.80 \\
0.83 \\
0.76\end{array}$ & $\begin{array}{l}0.41 \\
0.79 \\
0.81 \\
0.68\end{array}$ & $\begin{array}{l}0.38 \\
0.72 \\
0.74 \\
0.65\end{array}$ & $\begin{array}{l}0.71 \\
0.62\end{array}$ & $\begin{array}{l}0.67 \\
0.58\end{array}$ & & & \\
\hline
\end{tabular}

approximating the ratio generally found from conventional diffusion experiments, that is, about 0.1 . Thus, it should again be emphasized that, included in the "diffusion" obtained from these tetroon trajectories, is the lateral diffusion associated with meandering of the plume and the lateral diffusion associated with a turning of the mean wind with time.

Fig. 3 shows the average variation of lateral standard deviation with downwind distance for all launch sites. This was obtained by weighting the mean values for each launch site by the number of series which went into that value. Over the given downwind interval, in the mean, the lateral standard deviation is proportional to the 0.87 power of the downwind distance for the 3 -hr series and to the 0.85 power of the downwind distance for the 21 -hr series. This power may be estimated for longer time periods by means of the tetroon flights from Long Beach, since at this site tetroons were released continuously for a period of 116 hours. The 116-hr Long Beach series (Fig. 5) yields a lateral standard deviation proportional to the 0.84 power of the downwind distance. Thus, there is evidence than an increase in the time interval over which tetroons are released is associated with a slight decrease in the power describing the standard deviation versus the downwind relationship.

Fig. 3 shows, in addition, that for all tetroon launch sites the lateral standard deviation for the 21-hr series averages 1.52 times the lateral standard deviation for the 3 -hr series. This yields a lateral standard deviation proportional to the 0.21 power of the release time.

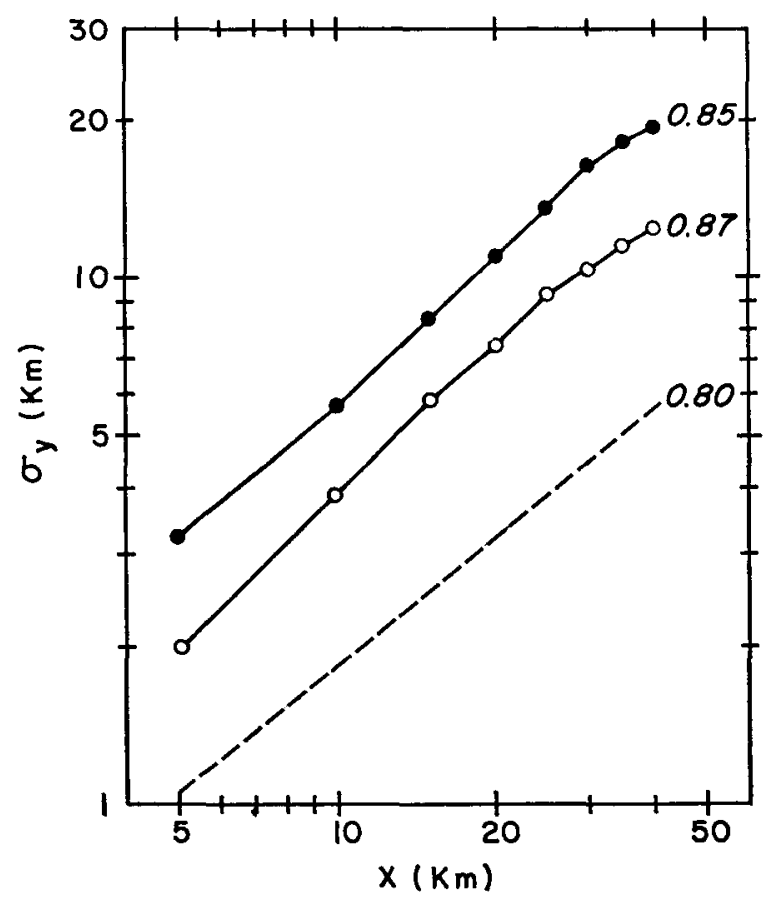

FIG. 3. Mean variation of lateral standard deviation with downwind distance for all tetroon launch sites and for time intervals of tetroon release averaging $3 \mathrm{hr}$ (circles) and $21 \mathrm{hr}$ (dots). The dashed line is extracted from Fig. 4.12 of Pasquill's book and represents the lateral standard deviation obtained from fluorescent particle experiments at Porton, England, and in New Mexico. The numbers indicate the power describing the standard deviation versus the downwind relationship. 


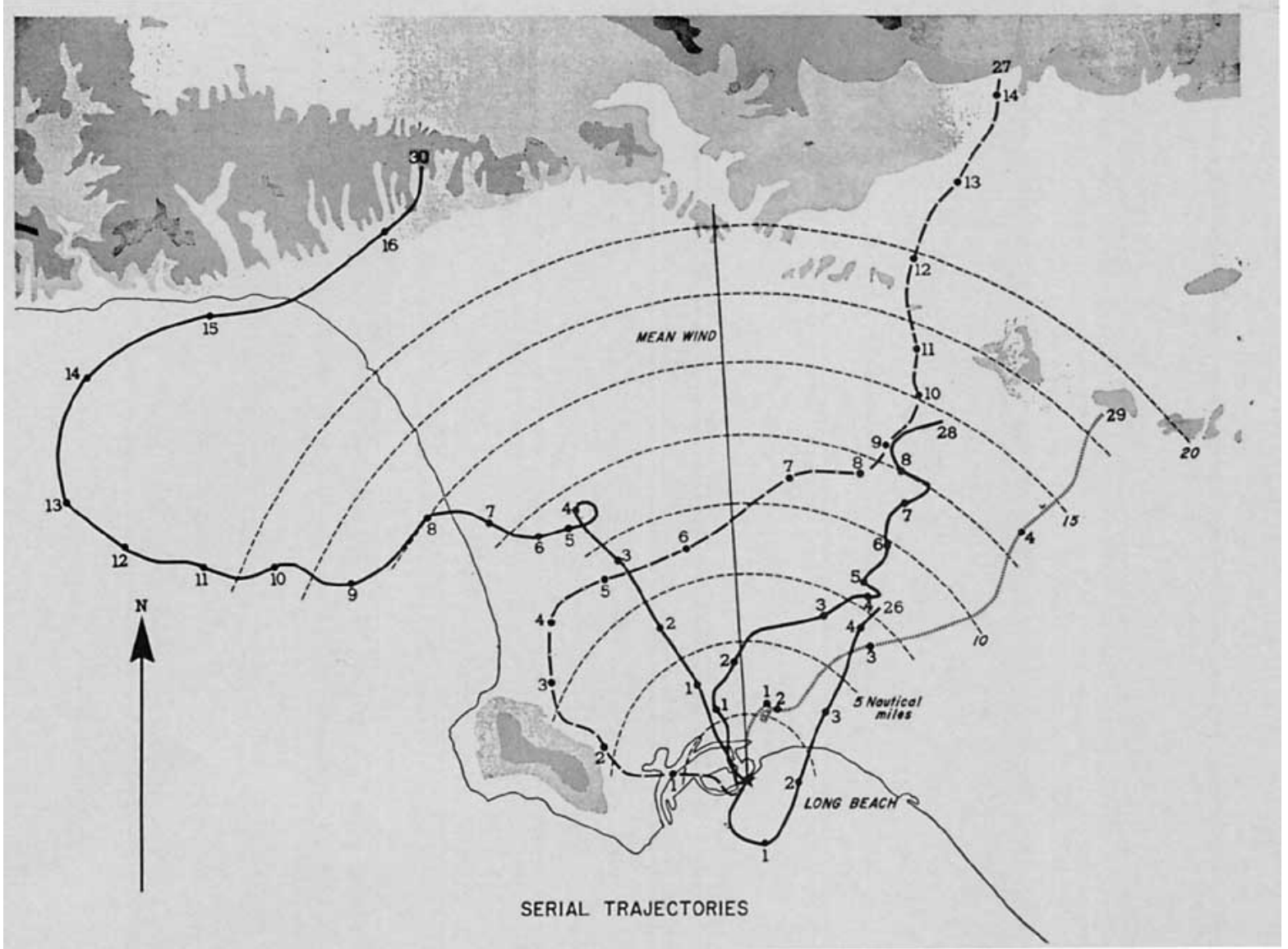

FIG. 4. Sample 24-hour trajectory series from Long Beach. Hours since tetroon release indicated along trajectories, flight numbers at ends of trajectories. Dashed arcs are the distances from the tetroon launch site in nautical miles. Solid, straight line is the estimated mean trajectory for the series. [See Pack and Angell (1963) for other Los Angeles tetroon trajectories.]

Insofar as one may relate release time and sampling time, this implies a lateral standard deviation proportional to the 0.21 power of the sampling time. On the basis of the Long Beach flights the average ratio of the lateral standard deviation, for time intervals of tetroon release of 116 and 21 hours, is 1.36 (Fig. 5). This indicates a lateral standard deviation proportional to the 0.18 power of the release (and sampling) time. There is some evidence that the proportionality of lateral standard deviation to about the 0.2 power of the release time also applies to shorter periods of release. Thus, the early Porton data suggested a lateral standard deviation of about $8 \mathrm{~m}$ at a downwind distance of $100 \mathrm{~m}$ and for a release duration of $4 \mathrm{~min}$ (Pasquill, 1962, p. 133). On the other hand, the Cardington tetroon data, in terrain similar to that at Porton, yield a lateral standard deviation of $0.9 \mathrm{~km}$ at a downwind distance of $5 \mathrm{~km}$, and for a release duration of $180 \mathrm{~min}$. If we assume the ratio of lateral standard deviation to downwind distance is invariant with downwind distance, we may write

$$
\frac{0.18}{0.08}=\left(\frac{180}{4}\right)^{a}
$$

which yields a lateral standard deviation proportional to the 0.21 power $(a)$ of the release time. This is identical to the mean value of 0.21 derived from tetroon releases over periods of $3 \mathrm{hr}$ and $21 \mathrm{hr}$ and close to the value of 0.18 derived from tetroon releases over periods of $21 \mathrm{hr}$ and $116 \mathrm{hr}$ and suggests that a power of approximately 0.2 may apply to a wide range of release and sampling times.

The dashed line in Fig. 3 is copied from Pasquill's (1962) Fig. 4.12 and represents his attempt to estimate the lateral standard deviation as a function of downwind distance from fluorescent particle experiments at Porton and in New Mexico. The lateral standard deviation derived from the fluorescent-particle technique is only about one-half that derived from the tetroons. If it is assumed that the lateral standard deviation varies as about the 0.2 power of the sampling time, then Pasquill's data would refer to a sampling time of approximately $4 \mathrm{~min}$. Pasquill states that for the fluorescent particle technique the sampling time should be considered $1 \mathrm{hr}$ or less so that there may well be a discrepancy here, probably due to the non-representative nature of the mean lateral standard deviation derived from the tetroon flights owing to the preponder- 
ence of flights within the Los Angeles Basin. This is also suggested by the observation that the lateral standard deviation derived from the 3-hr Cardington tetroon series agrees closely with Pasquill's curve.

At this point it is worthwhile to consider how the lateral standard deviations determined objectively from Eq. (1) compare with lateral standard deviations determined from trajectory series which were chosen subjectively. The latter had previously been selected on the basis that a mean wind could reasonably be defined for each series, as shown, for example, in Fig. 4. Fig. 5 shows how the values of lateral standard deviation obtained from four of these Long Beach Series (each of about 24-hr duration) compare with the lateral standard deviation obtained from all possible 21-hr Long Beach series as derived from Eq. (1) (14 such series). As might be anticipated, in attempting to choose series where a mean wind could reasonably be defined, we tended to underestimate the lateral diffusion actually associated with the Long Beach site at this time. However, this underestimate is not serious and it can be said, in all fairness, that the lateral standard deviation we derived from a subjective choice of trajectory series was fairly representative.

In summary, we conclude that the increased statistical reliability of the "pair" technique (Eq. 1), coupled with its objectivity, makes it a more reliable method. However, subjectively chosen trajectory series are fairly representative, if selected with care, and provide a useful visualization of the dispersion. We suggest that both methods be utilized, dependent upon the problem under study.

\section{Comparison of the lateral diffusion estimates from single tetroon flights and from serial flights}

It has been shown by Gifford (1960), Pasquill (1962) and others that the variance, or standard deviation, of lateral diffusion can be calculated from the running mean lateral wind fluctuations and that this is, theotheoretically, fully equivalent to using Taylor's (1921) original formulation involving double integration of the autocorrelation coefficient. The relevant formula is

$$
\sigma_{y(T)}=\left[v^{\prime}\left(T^{\prime}\right) T^{2}\right]^{\frac{1}{2}},
$$

where $\sigma_{y(T)}$ is the lateral standard deviation after travel time $T$, and $v_{(T)}^{\prime}$ is the variance of the lateral wind fluctuation averaged over the diffusion (or travel) time $T$. Values of $v^{\prime}$ were obtained by determining the mean direction of each tetroon flight (from the average of successive azimuths) and then calculating the component of the velocity normal to this mean direction. As a general rule, it is desirable to limit evaluation of $\sigma_{y(T)}$ to 10 per cent of the duration of the $v^{\prime}$ set (this is one of the chief drawbacks of this method). However, because of our relatively short trajectories, in the following we have computed $\sigma_{\mathcal{U}(T)}$ for travel times as large

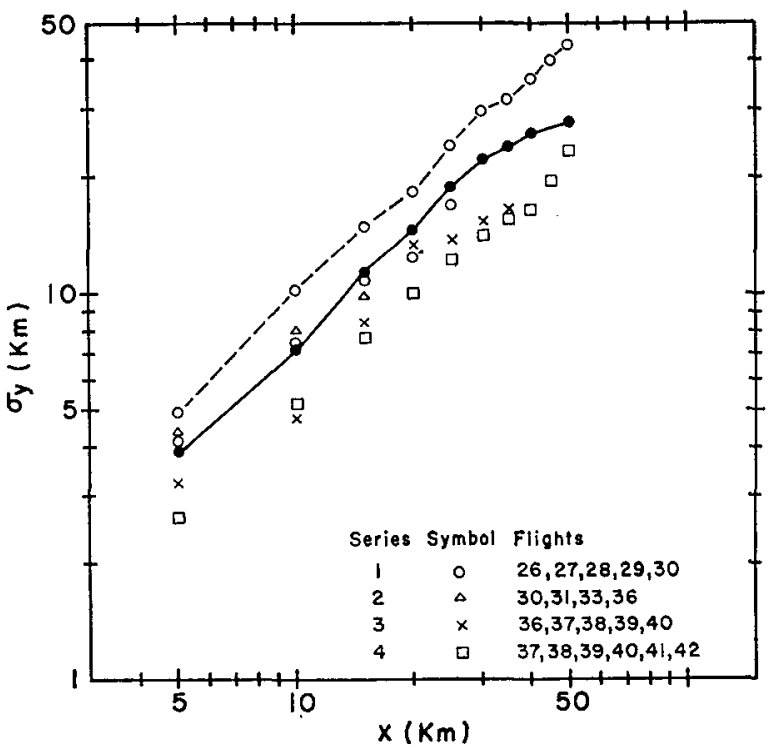

FIG. 5. Lateral standard deviation as a function of downwind distance for (subjectively chosen) 24-hr tetroon series from Long Beach (symbols), the average of the $21-\mathrm{hr}$ series from Long Beach obtained through use of Eq. (1) (solid line), and for all flights (116 hr series) from Long Beach (dashed line).

as 20 per cent of the duration of the $v^{\prime}$ set. Another drawback to this method is that radar positioning errors undoubtedly affect the $v^{\prime}$ statistics much more than the trajectories per se.

Calculations utilizing Eq. (3) have been made for several previous tetroon runs (Angell, 1962), but in these instances there were no simultaneous diffusion measurements by other techniques against which the values could be compared. Here we can compare the lateral diffusion evaluated from single flights with the values obtained from the series within which the single flights occurred. In order to do so, however, it is necessary to ensure that the "sampling" times for the two methods are compatible. That is, it is obvious that the lateral diffusion derived from a single 6-hr trajectory through the use of Eq. (3) would, in general, not be as large as the lateral diffusion derived from tetroon releases over a 24-hr period, since the 6-hr trajectory does not have an opportunity to sample the wind direction variations associated with the $24-\mathrm{hr}$ series. Consequently, in so far as possible, we have compared the lateral standard deviation obtained from Eq. (3) with the lateral standard deviation obtained from the trajectory series most nearly possessing the same time interval between first and last tetroon release as the duration of the trajectory in question. The first trajectory of the series is, of course, the trajectory to which Eq. (3) is applied. Even with this technique there is a small bias inasmuch as the last trajectory of the series is sampling wind-direction fluctuations which the initial trajectory does not sense, but it has not been possible to track sufficient tetroons simultaneously to make any other approach feasible. 


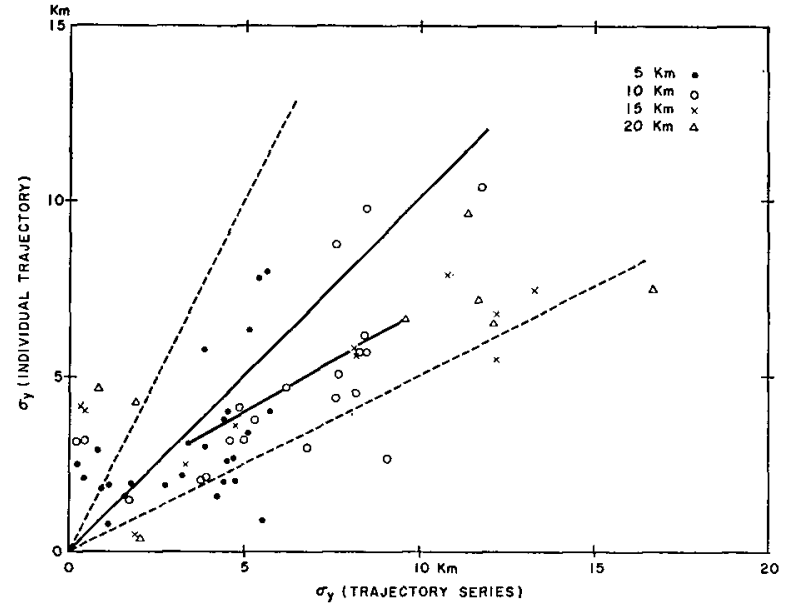

FIG. 6. Comparison, at various downwind distances, of the lateral standard deviation derived from trajectory series and from evaluation of the variance of running means of the lateral velocity along a single trajectory. The dashed lines indicate a difference exceeding a factor of two. The symbols connected by the solid line represent the average values obtained at the various downwind distances.

Through application of the above method, 25 lateraldiffusion comparisons were obtained for flights within the Los Angeles Basin. Comparisons could not be obtained at other tetroon Jaunch sites because at these other sites only one tetroon was tracked at a time. Even in the case of the Los Angeles flights, the trajectory series utilized were, in general, made up of only 3 trajectories so that also the lateral standard deviations derived from the series may not be overly representative. The average trajectory duration for the comparison was 7.5 hours while the average time interval between first and last tetroon release for the series was 9.6 hours. This difference in time interval introduces a small bias in addition to the one previously mentioned.

Fig. 6 illustrates the lateral standard deviations obtained by the two techniques at downwind distances of $5,10,15$ and $20 \mathrm{~km}$. As anticipated, particularly when the biases are considered, the lateral standard deviation derived from Eq. (3) generally is smaller than that derived from the series, although usually by not more than a factor of two. The average values at the various downwind distances are indicated by appropriate symbols and are connected by a solid line. At downwind distances of $5 \mathrm{~km}$ the two techniques yield such similar mean values that the use of Eq. (3) appears quite justified. However, as the downwind distance increases the comparison becomes poorer, until, at a distance of $20 \mathrm{~km}$, the mean lateral standard deviation derived from Eq. (3) is only 70 per cent of the mean derived from the series. This deterioration with increase in downwind distance would be expected because the low frequency lateral oscillations so effective in lateral diffusion at the greater downwind distances are poorly sensed by individual tetroon flights when the tetroon trajectories are relatively short.
A proper evaluation of the error involved in utilizing individual tetroon trajectories and Eq. (3) to estimate lateral diffusion must await simultaneous tetroon and tracer experiments. Such a comparison is now being made by F. Pooler at Cincinnati, Ohio (personal communication, 1964). Nevertheless, the comparison in Fig. 6 certainly suggests that the estimation of lateral diffusion by means of Eq. (3) is justified, particularly when the evaluation is made at a downwind distance which is a small fraction of the length of the trajectory to which (3) is applied. It might be noted that, for most purposes, the use of $\mathrm{Eq}$. (3) yields a value in error in a conservative sense; that is, since the lateral diffusion is underestimated, the effluent concentration is overestimated.

\section{The use of spectra to study lateral diffusion}

It is of interest to examine the spectra of the lateral wind fluctuations since these spectra graphically depict the periodicities responsible for the bulk of the diffusion. An example of such data are shown in Fig. 7. The solid line represents a composite spectrum of the lateral wind fluctuation obtained by averaging the individual spectra of 28 Los Angeles flights of at least 5 hours duration. Since the tetroon positions, obtained at 3-min intervals, were averaged for over-lapping 9-min intervals, spectral values are not presented for periods of oscillation shorter than $18 \mathrm{~min}$. It is seen that the variance per unit frequency interval increases rapidly at the lower frequencies (frequencies less than 0.01 cycle per min, or a period of $100 \mathrm{~min}$ ), presumably indicating the influence of the diurnal wind regime and perhaps other low frequency wind regimes. At frequencies near 0.04 cycle per minute (25 min period) there is a weak spectral peak in the composite spectrum. While it is unlikely, it is conceivable that this weak spectral peak is a reflection of the averaging process applied to the tetroon positions.

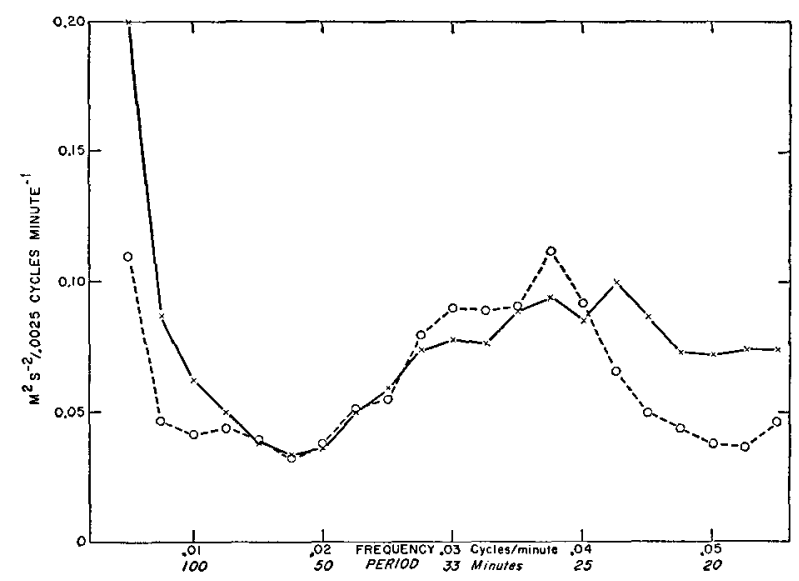

FIG. 7. Composite spectrum of Jateral velocity fluctuations for Los Angeles tetroon flights exceeding $5 \mathrm{hr}$ duration (solid line) and the difference between the spectrum for daytime flights and the spectrum for nighttime flights (dashed line). 
In order to examine this matter in more detail, a composite spectrum was obtained of the 6 "night" flights (flights aloft only between 1900 PST and 0700 PST) and of the 11 "day" flights aloft only between 0700 PST and 1900 PST). The remainder of the 28 flights were aloft during both day and night, as defined here, and hence were not utilized. The dashed line in Fig. 7 shows the mean difference, day minus night, of these two spectra. This difference is unaffected by the data averaging process. For all periods of oscillation the variance associated with lateral wind oscillations is greater for the "day" flights than for the "night" flights and the total daytime variance is greater by a factor exceeding two. The difference is most pronounced at periods near 25 minutes, suggesting some daytime mechanism which tends to produce lateral oscillations of 25-min period. Thus, while most of the dispersion within the Los Angeles Basin is associated with the diurnal wind regime, during the day an appreciable amount of the dispersion is associated with (Lagrangian) lateral wind fluctuations of about 25-min period. The physical nature of these latter periodicities is unknown and thus worthy of further study.

The composite spectrum may be used as a climatological tool to describe lateral diffusion. The collection and stratification of spectra for specified macro- and meso-meteorological regimes can provide insight into significant variations in the total diffusive capacity of a particular regime and to quantitative differences in the periodicities which predominate during the different situations. Acquisition of such data could permit a first order estimate of lateral diffusion from macro- or mesoscale synoptic analyses, and illuminate the physical causes more easily than the less descriptive dispersion statistics.

\section{Conclusion}

Serial tetroon releases may be utilized to provide lateral diffusion estimates for times and distances hitherto difficult to obtain. The lateral diffusion derived from a series consisting of only 2 trajectories is usually representative to within a factor of two. In most cases the lateral standard deviation derived from the variance of the running mean lateral velocity along a single trajectory also is representative to within a factor of two.
This latter result is of particular significance since it is logistically easier and certainly more rapid (excluding calculations) to obtain information from a single tetroon flight than from a series of tetroon flights. Furthermore, there appears to be no reason, in principle at least, why automation of the radar readout and appropriate computer links could not provide $\sigma_{y(T)}$ values immediately after completion of a single tetroon flight.

We must be careful in attempting to collate the results presented herein with those obtained by conventional techniques. Most conventional diffusion experiments have been carried out under conditions when there is little change in mean wind with time, and furthermore, the sampling period has generally been limited to less than one hour. However, included in the "diffusion" obtained by means of tetroon trajectories is the lateral diffusion associated with meandering of the plume and the lateral diffusion associated with the turning of the mean wind with time (plume meandering on a large time scale). In a sense, the very fact that the tetroon-derived diffusion data do not apply to specific weather regimes makes these data of special interest from a practical point of view.

\section{REFERENCES}

Angell, J. K., 1962: On the use of tetroons for the estimation of atmospheric dispersion on the mesoscale. Mon. Wea. Rev., 90, 263-270.

- 1964 : Measurements of Lagrangian and Eulerian properties of turbulence at a height of 2,500 ft. Quart. J. R. Meteor. Soc., 90, 57-71.

- $\ldots$, and D. H. Pack, 1961: Estimation of vertical air motions in desert terrain from tetroon flights. Mon. Wea. Rev., 89, 273-283.

- , and - 1962 : Analysis of low-level constant volume balloon (tetroon) flights from Wallops Island. J. Atmos. Sci., 19, 87-98.

Brier, G. W., 1950: The statistical theory of turbulence and the problem of diffusion in the atmosphere. J. Meteor., 7, 283-290.

Gifford, F. A., 1960: Atmospheric dispersion. Nuclear Safety, 1, 56-62.

Pack, D. H., 1962 : Air trajectories and turbulence statistics from weather radar using tetroons and radar transponders. Mon. Wea. Rev., 90, 491-506.

- - , and J. K. Angell, 1963: A preliminary study of air trajectories in the Los Angeles Basin as derived from tetroon flights. Mon. Wea. Rev., 91, 583-604.

Pasquill, F., 1962: Atmospheric Diffusion. London, Van Nostrand, $297 \mathrm{pp}$.

Taylor, G. I., 1921: Diffusion by continuous movements. Proc. London Math. Soc., ser. 2, 20, 196-212. 